\section{Por Que Estrógeno e Raloxifeno Melhoram a Densidade Mineral Óssea? Mecanismo de Ação do Estrógeno e de Um Modulador Seletivo do Receptor de Estrógeno (SERM) no Osso}

\section{RESUMO}

A deficiência de estrógeno é responsável pelo aumento na remodelação óssea após a menopausa, cuja prevenção é feita pela terapia de reposição hormonal com estrógeno: porém, ainda não está esclarecido o mecanismo da ação anti-reabsortiva do estrógeno no osso e permanecem várias questões: (1) Qual a célula-alvo de ação do estrógeno no osso? O receptor de estrógeno já foi descrito em monócito, osteoclasto, células do estroma da medula óssea e osteoblasto, mas é desconhecido o papel dessas células no efeito do estrógeno. (2) Quais os mediadores do efeito do estrógeno no osso? Os resultados da literatura são controversos quanto ao papel da interleucina-b, sendo a maioria dos resultados positivos em animais e não no homem. Outras citoquinas como interleucina- 1 e fator de necrose tumoral parecem estar envolvidos. (3) O efelto anti-osteoclástico do estrógeno está relacionado à apoptose de precursores dos osteoclastos? Já foi relatado. em animais, que o estrógeno aumenta apoptose dos precursores dos osteoclastos, porém não é conhecido esse efeito no homem. (4) Qual o papel do estroma da medula óssea na osteoclastogênese e na sua inibição pelo estrógeno? Recentemente foi descrito um fator, produzido pelas células do estroma (RANK ligante) que induz a formação de osteoclasto, sugerindo a importância dessas células na osteoclastogênese e no efeito do estrógeno no osso. (5) Qual a via de transcrição intracelular do efeito do estrógeno? Proteínas NF-kB podem ter um papel significante na osteoporose pós-menopausa, podendo corresponder à via pelo qual o estrógeno regula a produção de citoquinas envolvidas na osteoclastogênese, porém ainda não está esclarecido este efeito. Estas questões, sobre o mecanismo de ação do estrógeno, como também dos SERMs serão discutidas nessa revisão. (Arq Bras Endocrinol Metab 2000; 44/6: 471-82)

Unitermos: Estrógeno; Citoquinas; Osteoclasto: SERM; Receptor de estrógeno: Apoptose.

\author{
Ana Claudia R. Ramalho \\ Marise Lazaretti-Castro \\ Martine E. Coben-Solal \\ Marie Christine de Vernejoul
}

\author{
Disciplina de Endocrinologia e \\ Metabologia, Departamento de \\ Medicina, Universidade Federal de \\ São Paulo (UNIFESP-EPM), \\ São Paulo, SP e INSERM U349 - \\ Hospital Lariboisière, Paris, França
}

\begin{abstract}
Estrogen deficiency is responsible for increased bone furnover in the postmenopausal period, and it can be prevented by estrogen replacement therapy. The way by which estrogen acts on bone cells is not fully understood and there are still many unsolved questions: (1) What is the target-cell of estrogen in bone? Estrogen receptor has been described in monocyte, osteoclast, bone marrow stromal cell and osteoblast, but it is still not clear what cell mediates the effect of estrogen in bone. (2) What are the mediators of estrogen action on bone? There is some controversy about the role of interleukin-6; most of the positive results were in animals, not in human; other cytokines are also involved, as tumoral necrosis factor and interleukin-1. (3) Is the anti-osteoclast effect of estrogen related to the apoptosis of osteoclast precursors? Some authors had already reported that estrogen increase apoptosis of osteoclasts precursors in animals, but
\end{abstract}

Recebido em: 08/08/00 Revisado em: $28 / 11 / 00$ Aceito em: $30 / 11 / 00$ 
it is not clear whether this effect is also present in humans. (4) What is the role of the bone marrow in osteoclastogenesis and in its inhibition by estrogen? Recently, it has been shown that stromal cells produce a membrane-associated factor (RANK-ligand) that stimulates osteoclast precursors, showing the importance of stromal cells in osteoclastogenesis and probably in the effect of estrogen in bone. (5) What is the transcription mechanism of estrogen action into the cell? NF-kB proteins may have an important role in postmenopausal osteoporosis, by regulating the secretion of cytokines involved on osteoclastogenesis. These questions on the mechanism of action of estrogens and also SERMs will be discussed in this review based on studies of literature and on recent studies of our group. (Arq Bras Endocrinol Metab 2000; 44/6: 471-82)

Keywords: Estrogen: Cytokine: Osteoclast: SERM; Estrogen receptor; Apoptosis.

O STEOPOROSE DA PÓS-MENOPAUSA é uma desordem heterogênea caracterizada por perda óssea progressiva com início após menopausa natural ou cirúrgica, levando à ocorrência de fraturas 15-20 anos após a interrupção da função ovariana. Apesar de um baixo pico de massa óssea e da perda óssea fisiológica com o avançar da idade serem fatores contribuintes, um aumento na reabsorção óssea hormônio-dependente com acelerada perda da massa óssea nos primeiros 5 10 anos após a menopausa parece ser o fator patogênico determinante. Essa perda óssea na pós-menopausa pode ser restaurada pela terapia de reposição hormonal com estrógeno ( 1 ), porém ainda não está esclarecido o mecanismo de ação pelo qual esse efeito ocorre.

Durante os últimos anos, importantes avanços tem sido feitos no entendimento sobre a origem dos ostcoblastos e osteoclastos, da interação entre essas células, dos fatores sistêmicos e locais que regulam o desenvolvimento dessas células e do papel anti-reabsortivo ósseo do estrógeno, cujo mecanismo de ação ainda suscita várias questões.

Neste trabalho serão discutidos os conceitos e controvérsias atuais sobre o mecanismo de ação antireabsortivo ósseo do estrógeno e SERM (raloxifeno), baseados em resultados da literatura e em estudos recentes do nosso grupo.

\section{O OSTEOCLASTO}

Osteoclasto é uma célula volumosa multinucleada, contendo em média 10 a 20 núcleos por célula, situada em contato com o osso. Scu polo em contato com a matriz óssea forma dobras da membrana conhecidas como "bordas em escova" (2) e em cada extremidade dessa borda existem zonas de citoplasma desprovidas de organelas e pouco coradas, conhecidas como "zonas claras" (3). O osteclasto produz enzimas lisossomais como: fosfatase ácida tartarato resistente, presente na célula e no compartimento de reabsorção (4); as cisteínaproteinases (catepsinas) (5) e as enzimas não lisossomais como a colagenase e anidrase carbônica tipo II (6). Todas essas estruturas celulares especializadas delimitam uma área de reabsorção em que o osteoclasto, através da utilização de um mecanismo de redução do $\mathrm{pH}$ desta área, possibilita a reabsorção da matriz calcificada (7).

Já está bem estabelecido que o osteoclasto é originado de células hematopoiética da linhagem monócito-macrófago (8). Porém existem divergências quanto ao estágio onde a via de diferenciação de monócitos/macrófagos se separa daquela dos osteoclastos. Existem três teorias (9) (figura 1):

1) Osteoclastos seriam derivados de um progenitor específico, o CFU-O (Colony Forming UnitsOsteoclast), originado do CFU-S (Colony Forming Units-Stem);

2) Osteoclastos seriam derivados de CFU-GM (Colony Forming Units-Granulocyte Macrophage), precursor comum de osteoclasto como também de granulócitos e macrófagos;

3) Osteoclastos seriam formados à partir de monócitos circulantes e de macrófagos teciduais.

A primeira teoria é pouco provável, pois até o momento não foi evidenciado um precursor específico para osteoclasto (9). A segunda teoria é a mais provável, pois já foi evidenciada a capacidade do precursor CFU-GM de se diferenciar tanto em osteoclasto quanto em monócito circulante ou macrófago tissular (9). A terceira teoria já foi demonstrada por alguns autores em que o osteoclasto pode ser formado não apenas de células da linhagem monócito-macrófago imaturas, mas também de monócitos circulantes e de macrófagos teciduais quando o meio ambiente fornecido é adequado (10). Assim, as duas últimas teorias se constituem nas possíveis vias de recrutamento de osteclasto, fisiológica e patologicamente.

\section{PAPEL DO ESTROMA DA MEDULA ÓSSEA NA FORMAÇĀO DE OSTEOCLASTO}

Osteoclastogênese é um fenômeno complexo, facilitado pela integração dos precursores hematopoiéticos dos 


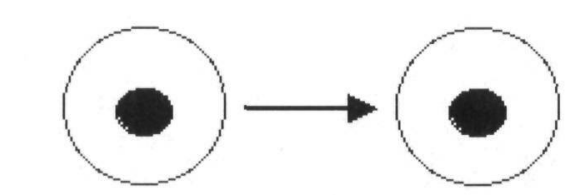

Célula de origem
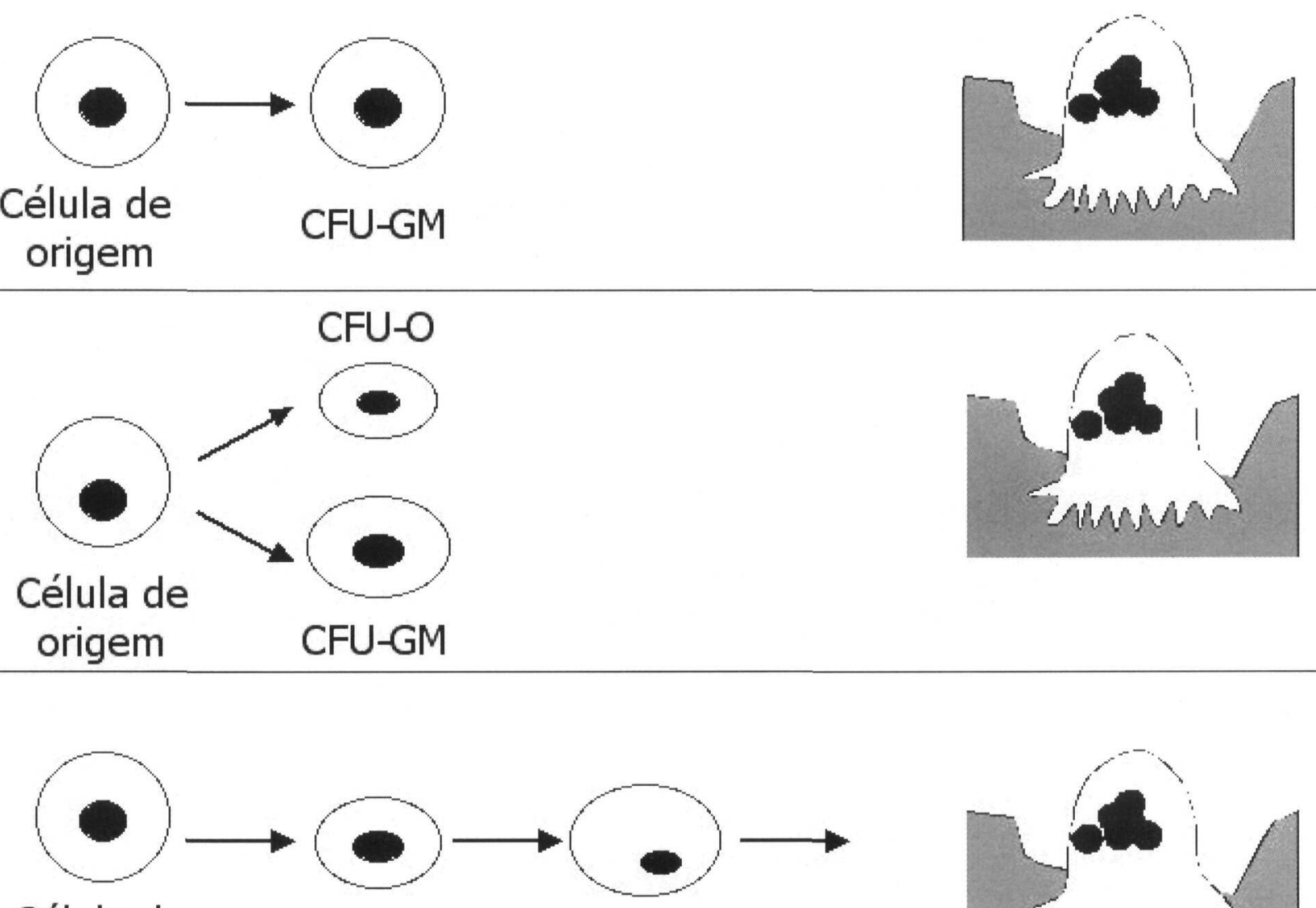

Célula de origem

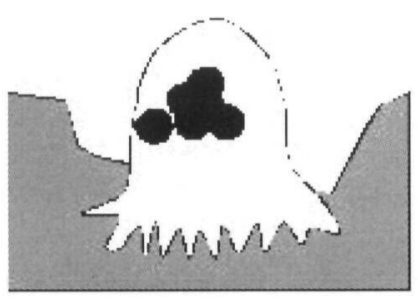

Figura 1. Modelos de diferenciação do osteoclasto.

Vários modelos têm sido propostos para a diferenciação do osteoclasto. Em um deles, a célula hematopoiética de origem forma a célula progenitora granulócito-macrófago, que então origina osteoclasto. Uma segunda possibilidade é que CFU-GM dá origem à monócito e monócito-macrófago maduro que formam osteoclasto. Em um terceiro modelo, a célula precursora hematopoiética dá origem à uma célula de origem única e específica para osteoclasto, CFU-O (osteoclast colony-forming cell) que é distinta da linhagem granulócito-macrófago. A célula se diferencia e fusiona para formar osteoclasto maduro.

osteoclastos com as células do estroma da medula óssea (células estromais). O estroma da medula óssea é morfologicamente heterogêneo e inclui fibroblastos, células osteogênicas e adipócitos. Existem evidências que essas células são derivadas de uma célula de origem única pluripotente que dá origem a progenitores de diferentes células mesenquimais (osteoblasto, adipócito, mioblasto, condroblasto c fibroblasto) (11). Essa células podem ser identificadas $\mathrm{em}$ cultura antes de sua diferenciaçào por um anticorpo monoclonal IgM, o Stro-1 (12).

As células estromais da medula óssea contribuem para osteoclastogênese, fornecendo um suporte físico para os osteoclastos como também pela produção de fatores de membrana solúveis e citoquinas que estimulam a proliferação e/ou diferenciação dos precursores hematopoiéticos dos osteoclastos (9).
Udagawa e cols (13) e Takahashi e cols (14) relataram que co-cultura de células precursoras de osteoclasto, como as células esplênicas ou de medula óssea associado às células estromais ou aos osteoblastos induzem a formação do osteoclasto. Porém, uma linhagem de células estromais de medula óssea de camundongo apresenta heterogeneidade na sua capacidade de favorecer osteoclastogênese (15). Células estromais ou osteoblastos que induzem a formação do osteoclasto devem ter capacidade de produzir MCSF (Macrophage-Colony Stimulating Factor), pois células estromais ou osteoblastos de camundongos $\mathrm{op} / \mathrm{op}$, deficientes de M-CSF, não são capazes de estimular a diferenciação do osteoclasto, sendo portadores de osteopetrose (16). M-CSF solúvel não substitui a necessidade das células estromais nesse sistema 


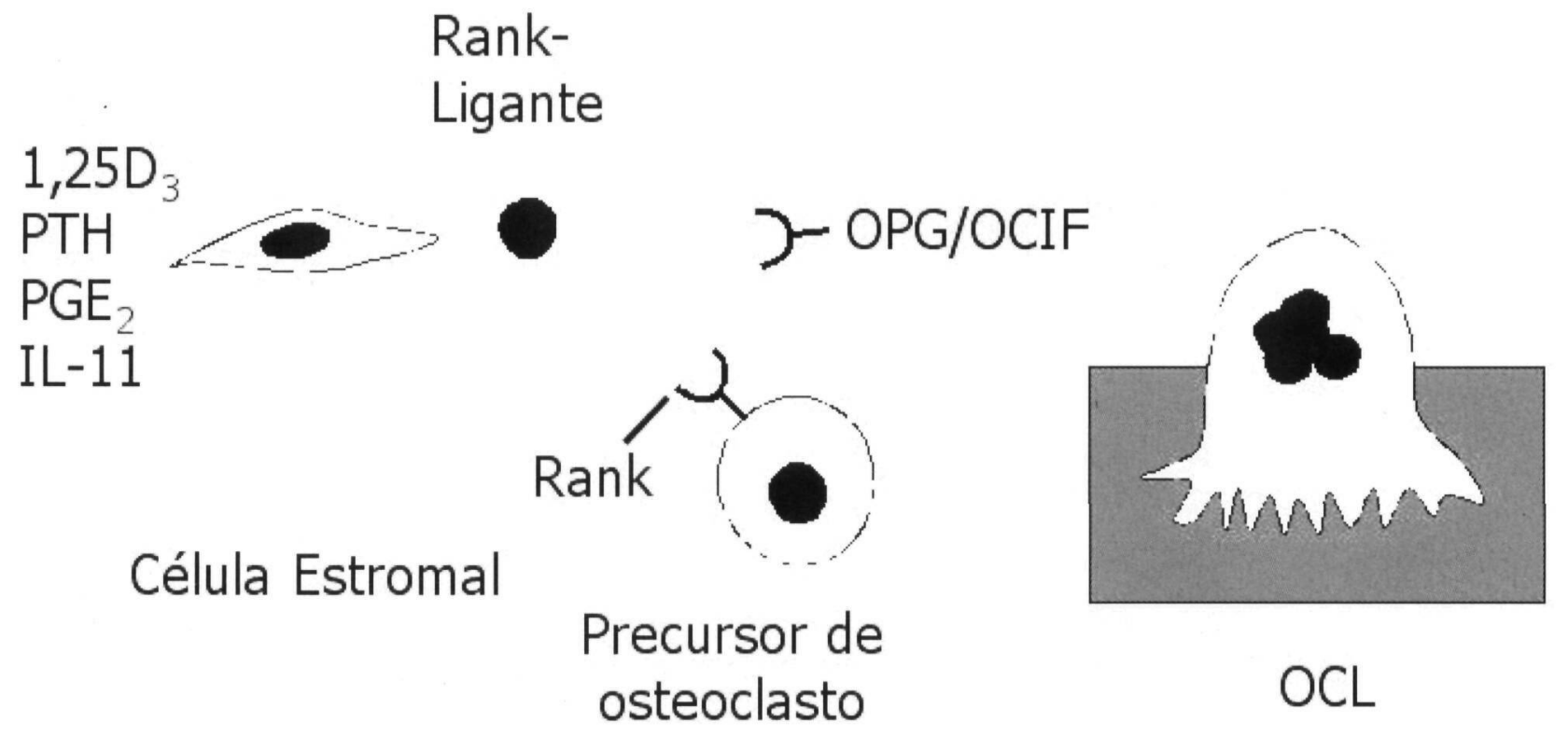

Figura 2. Papel do RANK ligante na osteoclastogênese.

Fatores osteotrópicos induzem uma regulação do RANK ligante (RANK-L) nas células do estroma da medula óssea e osteoblasto. RANK-L se liga co receptor de RANK no precursor do osteoclasto e induz a formação do osteoclasto.

de co-cultura, sugerindo que a ligação membranadependente de M-CSF ou outros fatores produzidos pelas células estromais ou osteoblastos são necessários para o desenvolvimento de osteoclastos à partir de seus precursores (16).

Recentemente, foi identificado um fator produzido pelas células estromais e pelos osteoblastos, que é crítico para a formação do osteoclasto. Esse fator é o RANK ligante (receptor activator of $N F-\kappa B$ ligand), também conhecido como TRANCE (TNF-related activation-induced cytokine), um novo membro da família do fator de necrose tumoral (TNF) (17). Yasuda e cols (17) mostraram que a maioria dos fatores osteotrópicos que induzem a formação de osteoclasto agem indiretamente se ligando a células estromais da medula óssea, que por sua vez induzem um aumento da expressão de RANK ligante (RANK-L), que então se liga ao receptor de RANK-L no precursor de osteoclasto e induz a formação de osteoclasto (figura 2).

A ausência de expressão do RANK-L em camundongos resulta $\mathrm{em}$ ausência de osteoclastos e osteopetrose (18). De forma inversa, uma expressão aumentada de RANK-L em camundongos transgênicos induz osteoporose severa.

$A$ atividade de RANK-L pode ser bloqueada por osteoprotegerina (OPG), também conhecida como fator inibidor da osteoclastogênese, que se constitui numa proteina relacionada ao receptor de TNF recen- temente identificado (19). OPG é produzida por diversos tipos celulares e bloqueia o estágio de fusão/diferenciação na diferenciação osteoclástica. Yasuda e cols (17) demonstraram que RANK-L, produzido pelos osteoblastos, se liga à OPG e bloqueia suas ações inibitórias na osteoclastogênese. Assim, RANK-L e OPG são importantes reguladores da formação e atividade do osteoclasto produzido pela medula óssea (figura 2).

\section{CITOQUINAS ENVOLVIDAS NA OSTEOCLASTOGÊNESE E REABSORÇĀO ÓSSEA}

Durante os últimos 15 anos, grande volume de conhecimento foi acumulado no campo das citoquinas, compreendendo também seu efeito no osso. Citoquinas são peptídeos mediadores locais que agem como fatores autócrinos e parácrinos na proliferação e/ou diferenciação das células ósseas, sendo envolvidas de forma fisiológica e/ou patológica no acoplamento entre reabsorção e formaçào óssea $(9)$.

Tanto osteoclastos quanto osteoblastos são derivados de precursores originados da medula óssca. O desenvolvimento dos osteoclastos depende da produçào de citoquinas pelas células da linhagem estro$\mathrm{ma} /$ osteoblasto (20). A importância das citoquinas no metabolismo ósseo é ainda confirmada pelo provável efeito de certos hormônios, como paratormônio 


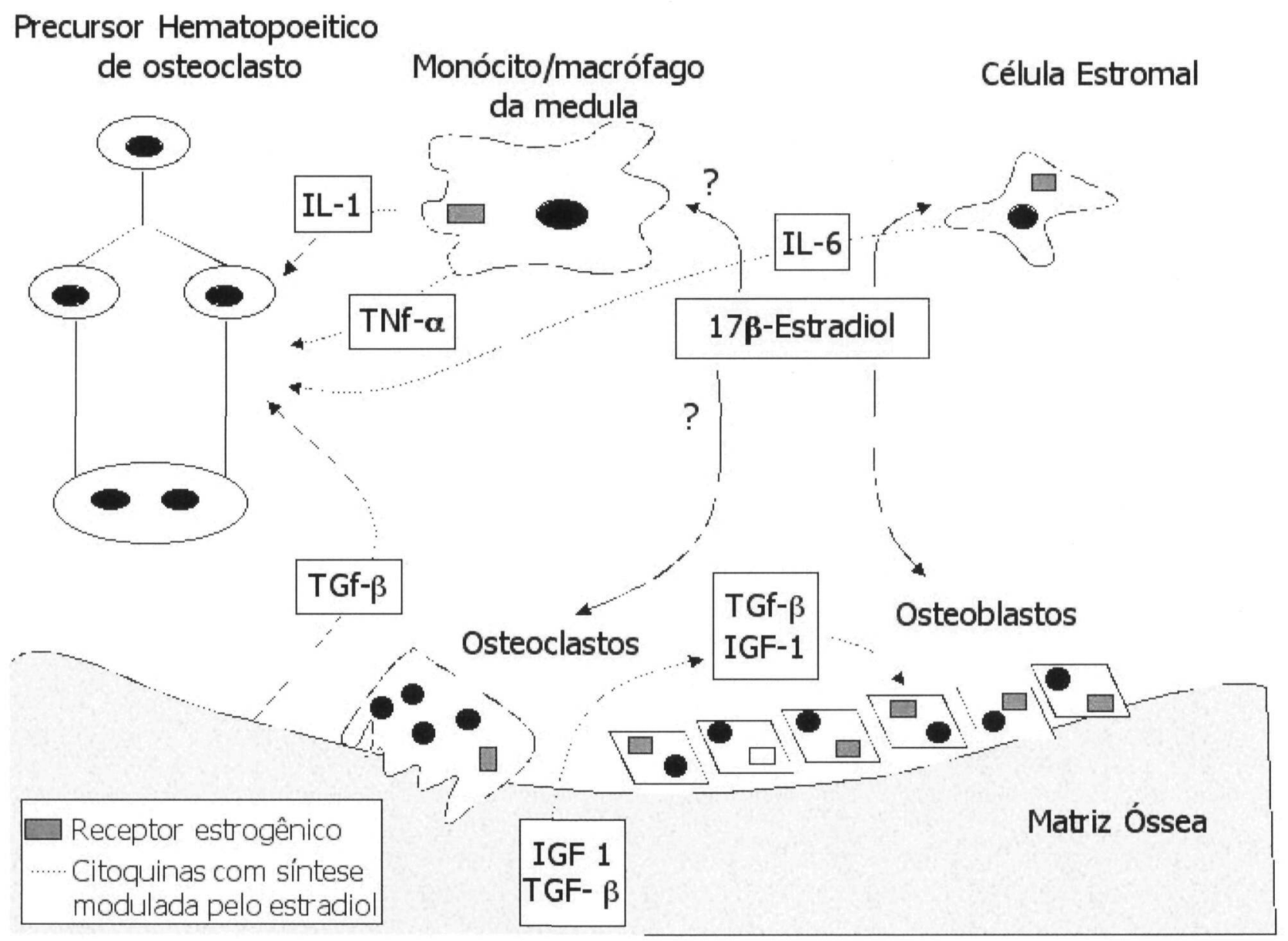

Figura 3. Efeito do estradiol nas células do osso e inter-relação com citoquinas.

Representação esquemática do conhecimento atual sobre o papel das citoquinas como mediadores locais do efeito do estradiol no osso. Estão representadas também questões sobre a célula-alvo do estrógeno, tendo em vista a presença de receptor de estrógeno já descrita nas diversas células representadas.

$\mid G F 1=$ Insulin-like Growth Factor 1; IL= Interleucina; TGF- $\beta=$ Transforming Growth Factor- $\beta$.

(PTH), regulando a produção e provavelmente a ação de citoquinas (21). A ausência de receptores de PTH nos osteoclastos com o potente efeito desse hormônio na reabsorção óssea, sugere que seu modo de ação é indireto e mediado por fatores locais como as citoquinas $(21,22)$. O conhecimento atual sobre o papel das citoquinas na comunicação entre as células ósseas está representado na figura 3 .

Várias citoquinas e fatores estimulantes de colônias tem sido implicados no desenvolvimento do osteoclasto e remodelação óssea. Esta lista incluc as interleucinas (IL-1, IL-2, IL-3, IL-6, IL-11), TNF, fator estimulante de colônia granulócito-macrófago (GM-CSF), M-CSF c fator inibidor de leucemia (LIF). Por outro lado, TGF- $\beta$ (transforming growth factor), IFN- $\gamma$ (interferon gama), IL-4 c IL-1 8 têm sido impli- cados como fatores inibidores do desenvolvimento de osteoclasto e remodelaçào óssea (23).

Evidências experimentais sugerem ainda o papel das citoquinas na patogênese de várias doenças ósseomctabólicas, como a doença de Paget e a osteoporose pós-menopausa. Assim, está claro que as citoquinas representam o ponto final de várias cascatas de eventos envolvendo hormônios sistêmicos, inflamação, infecção ou tumores $(22,24,25)$.

\section{Interleucina-6 (IL-6)}

IL-6 é produzida por várias células incluindo osteoblastos, células do estroma da medula óssea, monócitomacrófago, osteoclastos e $\mathrm{cm}$ resposta a estimulaçào de vários hormônios sistêmicos, como paratormônio (PTH), peptídeo relacionado ao PTH (PTHrp) e 1,25 
diidroxivitamina 103; de fatores de crescimento como TGFb e de outras citoquinas como interleucina-1 (IL-1) e fator de necrose tumoral (TNF) (22). IL-6 induz a formaçăo de osteoclasto à partir de precursores hematopoiéticos de osteoclasto, induzindo reabsorção óssea in vitro (26). Porém, alguns autores não evidenciaram efeito de IL- 6 na reabsorção óssea em células de calvária de camundongos neonatos que contém progenitores de osteoclastos já mais diferenciados e poucos progenitores mielóides primitivos considerados célulasalvo para ação de IL-6 (27). Contrapondo-se a esses resultados, a presença de receptores de IL-6 em células de osteoclastoma, sugere que IL- 6 deve influenciar não apenas estágios precoces do desenvolvimento do osteoclasto, mas também osteoclasto maduro (28).

IL-6 exerce seu efeito através de sua ligação à um receptor de membrana, levando à ativação de uma proteína intracelular, a glicoproteína-130 (gp 130) (29). O receptor solúvel de IL-6 (IL-6rs) não apresenta o domínio transmembrana e citoplasmático e traduz sinais através de gpl30, de forma semelhante à IL-6 (30); IL-6rs é gerado por proteólise do receptor de membrana de IL-6. Suda e cols (31) sugerem que a habilidade da IL-6 de estimular o desenvolvimento de osteoclasto requer a adição de IL-6rs exógeno e que a expressão do receptor de IL-6 pelos osteoblastos é indispensável para induzir formação de osteoclastos em co-culturas de osteoblastos com células esplênicas, porém isso não é confirmado por outros autores (26)

\section{Interleucina-1 (IL-I)}

IL-1 é uma citoquina produzida por células monócitos-macrófagos, células do estroma da medula óssea e osteoclasto que podem estimular reabsorção óssea in vitro e in vivo. IL-1 induz reabsorção óssea e formação de células osteoclasto-like em cultura de medula óssea em camundongos e em humanos (32). Recentemente, Uy e cols (33) usando um modelo in vivo de formaçào de osteoclasto para examinar os efeitos de IL-l nos diferentes estágios do desenvolvimento do osteoclasto, observaram que a IL-l induziu hipercalcemia e aumentou o crescimento e a diferenciação de GFUGM, o mais precoce precursor de osteoclasto. Além disso, aumentou o número de células mononucleares, precursor de osteoclasto e estimulou osteoclasto maduro para reabsorção óssea. Esses resultados suge rem que IL-l afeta todos os estágios do desenvolvimento de osteoclasto e pode explicar seu potente efeito na remodelação óssea in vivo.

\section{Fatores de Necrose Tumoral (TNF- $\alpha$ e TNF- $\beta$ )}

Tanto TNF- $\alpha$ quanto TNF- $\beta$ (linfotoxina) estimulam a formação de células multinuclcadas osteoclasto-like em cultura de medula óssea humana (32). Thomson e cols (34) demonstraram que co-cultura de osteoclasto maduro com osteoblasto em presença de IL-1 e TNF na cultura, estimulam a reabsorçào óssea. O efeito de TNF em estimular descnvolvimento de osteoclasto ocorre tanto através de um mecanismo dircto mitogênico no osteoclasto (32), quanto indireto, induzindo células estromais e osteoblasto a secretar citoquinas como M-CSF (35).

IL-1, TNF, IL-6 estimulam o desenvolvimento de osteoclasto, sendo que provavelmente esse efeito depende da presença de célula estroma/osteoblasto (22); representam uma cascata de citoquinas, cuja produção é regulada por vários estímulos, entre cles as próprias citoquinas. Assim, IL-1 e TNF estimulam a produção de IL-6 e algumas respostas de IL-1 e TNF são mediadas por IL-6 $(21,22)$.

\section{EFEITO ANTI-OSTEOPORÓTICO DO ESTRÓGENO}

Cinquenta por cento da perda óssea ligada a idade ocorre nos 8-10 anos seguintes à instalaçào da menopausa. Que esta perda está ligada a carência de estrógeno, isso é bem estabelecido e comprovado pela terapia de reposição hormonal (1), porém o mecanismo de açào anti-reabsortivo ósseo do estrógeno ainda não está esclarecido.

A maioria dos estudos avaliou o efeito do estrógeno sobre a diferenciação de osteoclastos utilizando animais ooforectomizados (36). Flanagan e cols (37), concordante com nossos resultados, demonstraram que o estradiol diminui a formação de células osteoclasto-like de medula óssca humana. Nossos resultados evidenciam uma redução dose dependente no número de células multinucleares TRAP+ (precursores de osteoclasto) após tratamento com estrógeno in vitro (Ramalho e cols, dados pessoais).

Existem evidências de que o efeito do estrógeno na osteoclastogênese é mediado por célula do estroma e/ou osteoblasto bascado na expressào de receptor de estrógeno $\alpha$ e $\beta$ nessas células (38-44).

\section{Receptor de Estrógeno $\alpha$ e $\beta$ (ER $\alpha$ e ER $\beta$ )}

Existem evidências da expressão ER $\alpha \mathrm{em}$ células do estroma da medula óssea $(38,39)$ e em osteoblasto $(42,43)$. Em nosso estudo (Ramalho e cols, dados pessoais) observamos que a síntese do receptor modificase durante a cultura de medula óssea total. Todas as culturas $(5 / 5)$ expressaram $E R \alpha$ no $5^{\circ}$ dia de cultura e apenas $1 / 5$ no $15^{\circ}$ dia, sugerindo que o efeito do estrógeno deva ocorrer no início da cultura. 
Mais recentemente foi descrito o ER $\beta$, porém sua distribuição e seu papel na ação do estrógeno no osso não estão esclarecidos (40). A expressão de ERß já foi descrita em célula do estroma c osteoblasto em ratos e humanos $(41,44)$, porém em nossas linhagens de células estromais, como também em cultura de medula óssea total, não encontramos expressão de ER $\beta$, sugerindo que a ação do estrógeno seja no ER $\alpha$ e não no $\operatorname{ER} \beta$ (Ramalho e cols, dados pessoais)

A expressão de ER $\alpha$ e/ou $\beta$ descrita na literatura em células do estroma da medula óssea e/ou osteoblasto e sua ausência em osteoclasto (45) reforçam a importância das células estromais como mediadoras da açào anti-reabsortiva do estrógeno no osso; como também a idéia de que as células do estroma podem modular o efeito do estrógeno através da liberação ou inibição de fatores, entre eles as citoquinas.

\section{Papel da Citoquinas na Reabsorçāo Óssea In- duzida pela Deficiência de Estrógeno}

Estudos recentes indicam o possível envolvimento de citoquinas (IL-1, IL-6 e TNF $\alpha$ ) na perda óssea ligada a deficiência de estrógeno. Alguns autores têm demonstrado que menopausa natural ou cirúrgica aumentam o nível de IL-1, IL-6, TNF e IL-6rs $(46,47)$.

Jilka e cols (36) demonstraram que a ação do estrógeno é mediada por IL-6. Estudando camundongos normais, evidenciaram que a ooforectomia aumenta o recrutamento de osteoclastos e esse efeito foi revertido com estrógeno e anticorpo anti-IL-6. Assim, sugerem que IL-6 estimula a osteoclastogênese nos estados de défict de estrógeno e que a ooforectomia aumenta não só a produção, mas também a resposta de precursores de osteoclasto à IL-6. Em outro estudo do mesmo grupo, Girassole e cols (48) demonstraram um efeito do estrógeno em reduzir os níveis de IL-6 basais e pós estímulo com IL-l e TNF em células estromais de medula óssea em camundongos.

Poli e cols (49), estudando camundongos transgênicos com deleção do gene para IL-6, observaram um volume de osso trabecular normal após ooforectomia; reforçando os resultados apresentados acima sobre o papel de IL-6 como mediador do aumento da reabsorção óssea na carência estrogênica.

Esses resultados são controversos e não confirmados por outros autores que não verificaram um efeito do estrógeno sobre a produção de citoquinas em culturas de medula óssea. Riggs e cols (50) demonstraram que o estrógeno não altera a produção de IL-6 basal ou após estimulação com IL-1 ou TNF em células humanas osteoblasto-like. Este mesmo grupo, uti- lizando outro modelo de estudo, encontrou um perfil de citoquinas semelhante em medula óssea de mulheres tratadas com estrógeno, comparadas às não tratadas, tanto in vivo quanto in vitro (51). Esses resultados sugerem a ausência do efeito do estrógeno sobre a produção de IL-6 em diferentes modelos de estudo.

Ainda concordante com esses resultados, Lorenzo e cols (52) não observaram alteração na expressão de IL-6 em células da medula óssea de camundongos após ooforectomia e posterior tratamento com estrógeno, tanto in vivo quanto in vitro.

Em estudos do nosso grupo, Cohen-Solal e cols (53) encontraram o mesmo perfil de citoquinas em sangue periférico em mulheres tratadas com estrógeno em comparação com as mulheres sem tratamento e Ramalho e cols (dados pessoais) encontraram uma redução do número precursores de osteoclasto, cm cultura de medula óssea humana após tratamento com estrógeno in vitro, porém sem alteraçào nos níveis de IL-6 e IL-6rs nessas culturas. Assim, a maioria dos estudos em células estromais e ostcoblasto humano expressando receptor de estrógeno falhou em demonstrar efeito do estrógeno na produção de IL-6.

Essas divergências de resultados entre os diversos estudos podem ser secundárias às diferenças dos sistemas in vitro, dificuldade de reprodução dos modelos de estudo, níveis basais heterogêneos na produção de citoquinas, variabilidade na resposta dessas culturas primárias ao estradiol, diferenças entre espécies; por exemplo, o efeito do estrógeno na produção de IL-6 pelas células estromais foi evidenciado em animais $(49,54)$, porém não $\mathrm{cm}$ célula do estroma/ osteoblasto humano $(51,52)$. Beresford e cols $(55)$ relataram várias diferenças entre células estromais $\mathrm{cm}$ ratos e humanos, que poderiam explicar esses resultados divergentes.

Outras citoquinas, além da IL-6, produzidas pelos célula do estroma/osteoblasto devem ter um papel na osteoporose pós-menopausa. Estradiol parece influenciar a secreção de IL-1 (56) e TNF- $\alpha$ (50) dos osteoblastos humanos. Monócitos periféricos circulantes de pacientes ooforectomizados produzem níveis elevados de IL- 1 e TNF- $\alpha$, sendo esse efeito antagonizado pela reposição estrogênica (23). Concordante com esse resultado, Cohen-Solal c cols (53) obscrvaram que o sobrenadante de cultura de monócitos periféricos de mulheres na pós-menopausa tem atividade reabsortiva aumentada in vitro, a qual era bloqueada pelos anticorpos: anti IL-l ra e TNF. Manolagas (54), por outro lado, sugere que o aumento de IL1 e TNF em animais ooforectomizados é conseqüên- 
cia da remoção do efeito inibidor do estrógeno sobre IL-6. Assim, IL-1 e TNF diferentemente de IL-6, não seriam diretamente suprimidos pelo estrógeno.

Tendo em vista a demonstração da expressão de receptores de estrógeno em células do estroma/ osteoblasto e não $\mathrm{em}$ osteoclasto, podemos imaginar o seguinte modelo para explicar o mecanismo de ação do estrógeno no osso: o aumento da reabsorção óssea decorrente da carência estrogênica pode ser conseqüente a um aumento da secreção pelos osteoblastos ou pelas células do estroma da medula óssea de fatores, como as citoquinas, capazes de estimular a osteoclastogênese e um aumento da reabsorção óssea. Dentro desse modelo podemos incluir ainda o efeito do estrógeno na apoptose de osteoclastos c/ou de seus precursores $(36,37)$.

\section{Estrógeno e Apoptose}

Conforme já demonstrado $(36,37)$, o estrógeno reduz o recrutamento de osteoclasto c/ou seus precursores. Alguns estudos têm sugerido que esse efeito do estrógeno seria decorrente de um incremento na apoptose de osteoclasto $(57,58)$. Hughes e cols $(58)$ demonstraram que $17 \beta$-estradiol promove um incre mento na apoptose de osteoclastos em camundongos em 2 a 3 vezes e que esse efeito é mediado por TGF$\beta$. Nossos resultados não confirmaram um efeito do estrógeno na apoptose de precursor de osteoclasto em

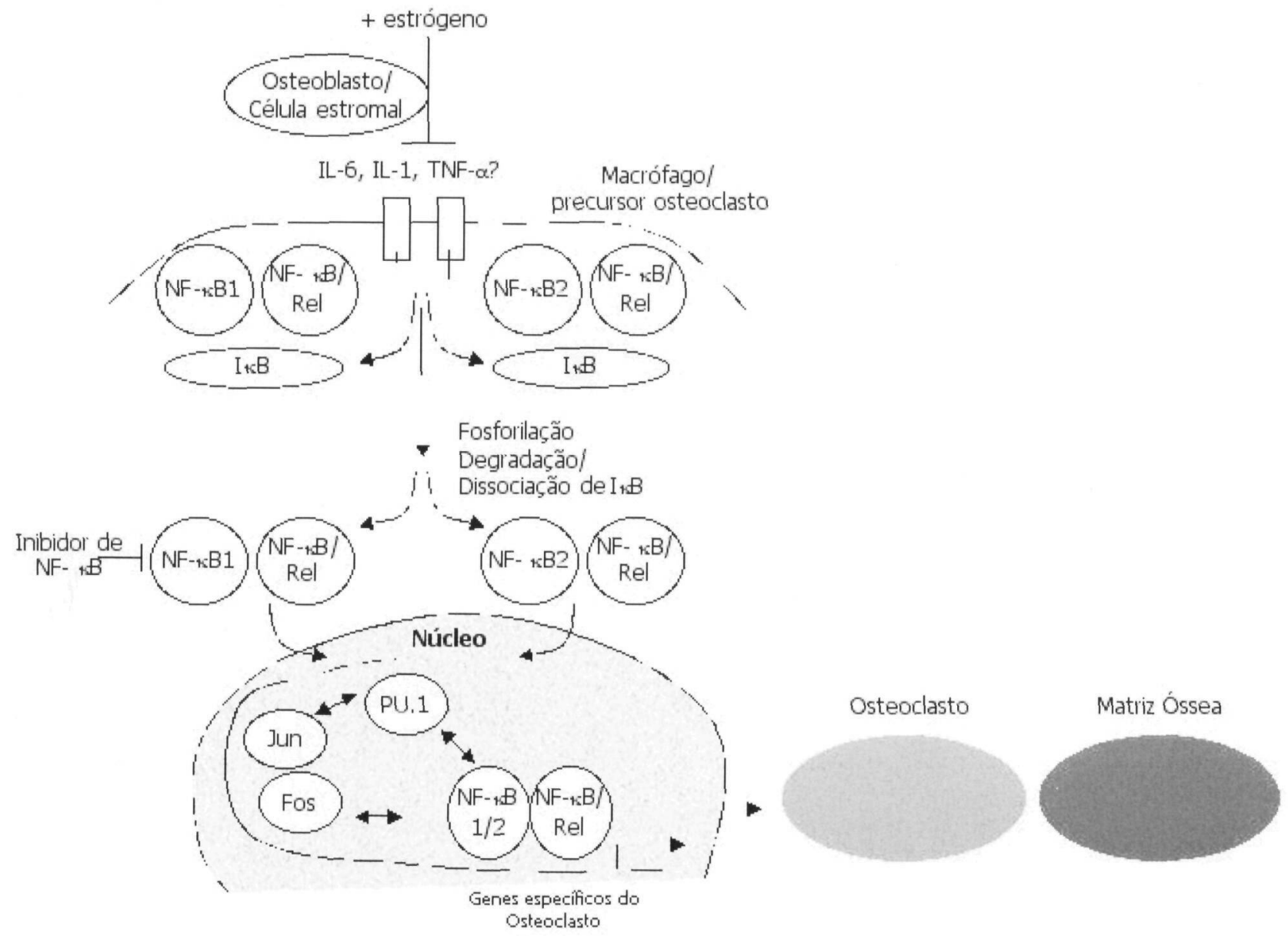

Figura 4. NF-kB e Osso.

Durante a remodelação óssea normal, existe um balanço entre atividade do osteoblasto e do osteoclasto. A mulher na pós menopausa experimenta uma redução na densidade mineral óssea secundária a um aumento no número e atividade dos osteoclastos. O osteoclasto se diferencia em resposta às citoquinas, tais como: IL-1, IL-6 e TNF- $\alpha$, que são produzidas pelos osteoblastos e células do estroma da medula óssea. Redução dos niveis de estrogênio promovem produção dessas citoquinas que diferenciam o precursor comum macrófago/ osteoclasto na direção da linhagem osteoclástica. Cada uma

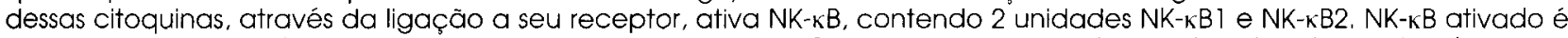
translocado para o núcleo e em cooperação com c-fos e PU.1, promovem diferenciação do osteoclasto através da ativação de genes específicos. 
medula óssea humana, utilizando o método TUNEL que avalia a fragmentação internucleossomal do DNA, característica da apoptose (Ramalho e col, dados pessoais). A maioria desses estudos avaliou a apoptose de osteoclastos e/ou seus precursores em animais, sendo necessário um maior número de estudos em humanos para elucidação desse efeito.

\section{Estrógeno e Fator Nuclear $k B(N F-\kappa B)$}

A família de fatores de transcrição NF-кB/Rel regula a expressão de uma série de genes alvos envolvidos no desenvolvimento $e$ imunidade. Proteínas NF-KB podem ter um papel significante na osteoporose pósmenopausa regulando a produção de citoquinas (59) (figura 4).

Existe evidência de que o estrógeno iniba a produção de IL-6 pelos osteoblastos via receptor de estrógeno, que previne a ligação dos fatores de transcrição NF- $\mathrm{kB}$ e NF-IL6 com seus respectivos elementos resposta do DNA no promotor de IL-6 (60).

É bem conhecido que a ativação de NF- $\kappa$ B é estritamente regulada por seu inibidor endógeno $(\mathrm{IkB} \alpha)$ que pode estar fisicamente associado com NF$\kappa B$. A expressão da forma ativa de NF- $\kappa B$ é induzida por diversos estímulos como IL-1, IL-2, TNFo e PMA (phorbol 12-myristate 13-acetate). Esses estímulos parecem ativar NF- $\mathrm{B}$ através da indução da fosforilação e liberação de $\mathrm{IkB} \alpha(60)$, dessa forma permitindo a rápida translocação de NF- $\kappa B$ do citoplasma para o núcleo (figura 4 ).

Sun e cols (60) demonstraram que o tratamento $\mathrm{com}$ estrógeno inibe a degradação protéica $\operatorname{IkB} \alpha$ induzida por PMA e que um provável efeito do estrógeno scria na manutenção de $\operatorname{IkB} \alpha$ e, portanto, a inativação de NF-кB. Outros autores, por sua vez, evidenciaram o efeito da via PKC (proteína C-quinase) para biossíntese e secreção de IL-6 em diferentes células, inclusive em células do estroma de medula óssea humana $(61,62)$. Kim e cols $(61)$ não encontraram efeito do estrógeno na produção constitutiva de IL-6 em células de medula óssea humana, porém o nível de IL-6 diminuiu com estrógeno em células estimuladas com PMA (estimulador da via PKC).

\section{SERMs (Selective Estrogen Receptor Modulators)}

A compreensão do mecanismo de ação do estrógeno poderá levar ao entendimento também do mecanismo de ação dos moduladores seletivos do receptor de estrógeno (SERMs). SERMs são uma nova classe de moléculas não hormonais que se ligam à receptores de estrógeno e podem funcionar como agonista ou antagonista do estrógeno na dependênca do tecido-alvo. $O$ conceito de SERM nasceu a partir de constatações feitas com o tamoxifeno. Alguns estudos mostraram que o tamoxifeno previne parcialmente a perda óssea nas mulheres menopausadas e promove uma redução sérica do colesterol $(63,64)$, mas a utilizaçào prolongada do tamoxifeno aumenta o risco de câncer de endométrio.

Os resultados com o raloxifeno, primeiro SERM de segunda geração, são importantes. Um estudo multicêntrico europeu em 602 mulheres recémmenopausadas, mostrou que o raloxifeno induz um ganho mineral ósseo de $2-4 \%$ na coluna lombar, fềmur proximal e corpo total, em comparação à perda significativa do grupo placebo. Este efeito está ligado a uma redução da remodelação óssea, com as taxas dos marcadores de reabsorção e formação óssea tornando-se semelhante aos valores de mulheres não menopausadas (65). Informações complementares foram dadas pelo estudo MORE (Multiple Outcomes of Raloxifen Evaluation), realizado em 7.705 mulheres pós-menopausadas osteoporóticas, quando foi evidenciado uma diminuição em $50 \%$ na incidência de novas fraturas vertebrais em 36 meses de tratamento com raloxifeno, em comparação com placebo (66).

O mecanismo de ação molecular do raloxifeno envolve alta afinidade de ligação com o receptor de estrógeno, provocando alteração conformacional na estrutura do receptor, sua dimerizaçào e associação com elementos resposta do DNA, já tendo sido descrito sítios de ligação do DNA, elementos resposta específicos para o raloxifeno e distintos do estrógeno (67). Estrógeno e raloxifeno podem ativar a transcrição de genes que codificam TGF $\beta$ e que junto com outras citoquinas induzem a produção de osteoblasto e inibem a atividade e/ou a vida média do osteoclasto (67).

Dados de histomorfometria em ratos ooforectomizados tratados durante cinco semanas com raloxifeno ou estradiol, demonstram que raloxifeno, mimetizando a ação do estadiol, preveniu a perda óssea trabecular, através de um efeito anti-reabsortivo ósseo, como evidenciado pela redução no número de osteoclastos (68). Concordante com esse efeito, encontramos, após tratamento com raloxifeno, uma redução no número de células multinucleares TRAP+, precursores osteoclastos, em cultura de células de medula óssea humana (Ramalho e col, dados pessoais).

A habilidade do raloxifeno de provocar uma resposta tecido-seletiva parece estar relacionada com a diversidade de proteínas associadas ao receptor nos diferentes tecidos (co-ativadores, co-repressores, fatores de transcrição), com a diferente distribuição dos subtipos do receptor de estrógeno $(\alpha$ e $\beta)$ nos teci- 
dos e com a ativaçào de diversos elementos resposta em diferentes genes.

\section{MODELOS DE ESTUDO IN VITRO DESENVOLVIDOS PARA ESTUDO DOS EFEITOS DO ESTRÓGENO E OUTRAS SUBSTÂNCIAS SOBRE O OSSO}

Vários sistemas de cultura de células provenientes de diferentes espécies têm sido elaborados para estudar o mecanismo celular e molecular da osteoclastogênese e o efeito do estrógeno sobre esse processo. Quatro categorias podem ser descritas (69):

1) Osteoclastos desenvolvidos a partir de monócitos (de sangue periférico, de sangue do cordão umbilical, de origem esplênica ou linhagem de célula monocítica) cultivadas na presença de células estromais (linha de célula osteoblástica);

2) Co-cultura de células da medula óssea: cultura de células da fração mononuclear cultivadas com adequada linhagem de células estromais ou com osteoblastos;

3) Cultura de células mononucleares da medula óssea na presença de seroma e vários fatores solúveis;

4) Formação de osteoclasto a partir de cultura de células de medula óssea total (células hematopoiéticas e células do estroma). As células multinucleares são formadas por mecanismo de fusão de precursores mononucleares na presença das células estromais da medula óssea total e que aderem em cultura in vitro durante a cultura.

Todos esses modelos de estudo apresentam suas limitações para mimetizar de forma adequada o meio ambiente ósseo $e$, portanto, poder reproduzir de forma eficaz in vitro os mecanismos e substâncias que intervém na remodelação óssea. Apesar da melhora no método de isolamento de osteoclastos maduros $(70,71)$, vários inconvenientes limitam sua utilização: o número escasso dessas células, a impureza das preparações, a baixa viabilidade das células em cultura e o seu dificil acesso no homem. Essas células chegam ao fim da diferenciação e não mais se dividem, podendo assim ser mantidas em cultura apenas durante poucos dias.

A ausência de um modelo in vitro com boa reprodutibilidade do meio ambiente ósseo tem dificultado um entendimento claro dos mecanismos envolvidos na remodelação óssea, como também do mecanis- mo de ação de drogas anti-reabsortivas ósseas, como o estrógeno.

Em resumo, o efeito anti-osteoclasto do estrógeno e do raloxifeno está relacionado à redução do número de células precursoras de osteoclasto, sendo controverso se esse efeito é mediado pela IL-6 ou ainda se está relacionado à apoptose dessas células. O efeito do estrógeno no osso parece ser mediado pelo $\mathrm{ER} \alpha$, não estando esclarecido o papel do ERß. Quanto à via de transcrição intracelular do efeito do estrógeno, existem evidências de que o estrógeno inibe a produçào de IL-6 pelos osteoblastos via receptor de estrógeno, que previne a ligação dos fatores de transcrição NF- $\mathrm{KB}$. As dificuldades no avanço do entendimento do mecanismo de ação do estrógeno $\mathrm{c}$ SERMs está relacionada às limitações dos diversos modelos de estudo para mimetizar de forma adequada o meio ambiente ósseo e portanto poder reproduzir in vitro de forma eficaz os mecanismos e substâncias que intervêm na remodelação óssea

\section{REFERÊNCIAS}

1. Riggs BL, Melton III LJ. The prevention and treatment of osteoporosis. N Engl J Med 1997;327:620-7.

2. King GJ, Holtrop ME, Raisz LG. The relation of structural changes in osteoclasts to resorption in bone cultures stimulated with parathyroid hormone. Metab Bone Dis Res 1978: 1:67-74.

3. King GJ, Holtrop ME. Actin-like filaments in bone cells of cultured mouse calvaria as demonstrated by binding to heavy meromyosin. J Cell Biol 1975:66:445-51.

4. Baron R. Molecular mechanisms of bone resorption by the osteoclast. Anat Rec 1989:224:317-24.

5. Delaisse JM, Eeckhout $Y$, Neff L, Francois-Gillet C. Henriet $P$, Su $Y$, et al. Procollagenase matrix metalloprotease1 is present in rodent osteoclasts and in the underlying bone-resorbing compartment. J Cell Science 1993; 106: 1071-82.

6. Gay C. Mueller WJ. Carbonic anhydrase and osteoclasts: localization by labeled inhibitor autoradiography. Science 1974;183:432-4.

7. Teitelbaum SL, Abu-Amer $Y$, Ross FP. Molecular mechanisms of bone resorption. J Cell Biochem 1995;59:1-10.

8. Walker DG. Osteopetrosis cured by temporary parabiosis. Science 1973; 180:875.

9. Suda T, Takahashi N, Martin TJ. Modulation of osteoclast differentiation. Endoc Rev 1992; 13:66-80

10. Udagawa N, Takahashi N, Akatsu T, Tanaka H, Sasaki T, Nishihara $\mathrm{T}$, et al. Origin of osteoclast: mature monocytes and macrophages are capable of differentiating into osteoclast under a suitable microenviroment prepared by bone marrow-derived stromal cells. Proc Natl Sci USA 1990:87:7260-4. 
11. Owen MME, Cave J, Joyner CJ, Clonal analysis in vitro of osteogenic differentiation of marrow CFU-F. J Cell Sci $1987 ; 87: 731-8$.

12. Gronthos S, Simmons PJ. Growth factor requirements of STRO-1 positive human bone marrow stromal precursors under serum-deprived conditions in vitro. Blood 1995:85:929-40.

13. Udagawa N, Takahashi N, Akatsu T, Sasaki T, et al. The bone marrow derived stromal cell lines MCT3T3-G2/PA6 and ST2 support osteoclast-like cell differentiation in cocultures with mouse spleen cells. Endocrinology 1989:125:1805-13.

14. Takahashi N, Akatsu T, Udagawa N, et al. Osteoblastic cells are involved in osteoclast formation. Endocrinology 1988: $123: 2600-2$.

15. Takanashi H. Matsuishi T, Yoshizato K. Establishment and characterization of stromal cell lines that support differentiation of murine hematopoietic blast cells into osteoclast-like cells. Cell Dev Biol 1994;30 A:384-93.

16. Kodama H, Nose M, Niida S, Yamasaki AA. Essential role of macrophage colony-stimulating factor in osteoclastdifferentiationsuppoerted by stromal cells. J Exp Med 1991;173:1291-4.

17. Yasuda H, Shima N, Nakagawa N, et al. Osteoclast differentiation factor as a ligand for osteoprotegrin/osteoclast inhibitory factor and is identical to to TRANCE/RANKL. Proc Natl Acad Sci USA 1998:95:3597-602.

18. Tsukki K, Shima, N, Mochizuki S, et al. Osteoclast differentiation factor mediates na essencial signal for bone resorption induced by 1 alpha, 25 dihydroxivitamin D3. prostaglandin E2 or parathyroid hormone in the microenviroment of bone. Biochem Biophys Res Comm $1998 ; 246: 337$.

19. Simonet WS, Lacey DL, Dunstan CR, et al. Osteoprotegerin: a novel secreted protein involved in the regulation of bone density. Cell 1997:89:309-19.

20. Romas $E$, Martin TJ. Cytokines in the pathogenesis of osteoporosis. Osteopor Int 1997:7:s47-s53.

21. Kim GS, Kim CH, Cheol S, Park JY, Lee K. Involvement of different second messengers in parathyroid hormoneand interleukin- 1 -induced interleukin- 6 and interleukin11 production in human bone marrow stromal cells. J Bone Miner Res 1997; 12:896-902.

22. Manolagas SC, Jilka RL, Girasole G, Passeri G, Bellido T. Estrogen, cytokines and the patophysiology of osteporosis. In: Kohler PO, ed. Current Opinion in Endocrinology and Diabetes. Philadelphia; Current Science. 1994:275-281.

23. Pacifici R, Rifas L, Mcracken R, et al. Ovarian steroid treatment blocks a postmenopausal increase in blood monocyte interleukin-1 release. Proc Natl Acad Sci USA $1989: 86: 2398-402$

24. De Vernejoul MC, Cohen-Solal M, Orcel P. Bone cytokines. Curr Opin Rheum 1993:5:332-8.

25. Suda T, Miyaura C. Pathogenesis of bone loss due to estrogen deficiency. Osteop Int 1997;7:s43-s46.

26. Kurihara N, Bertolini D, Suda T. Akiyama Y, Roodman GD. IL-6 stimulates osteoclast-like multinucleated cell forma- tion in long-term human marrow cultures by inducing IL1 release. J Immunol 1990; 144:4226-230.

27. Al-humidan A, Ralston SH, Hughes DE, ef al. Interleukin- 6 does not stimulate bone resorption in neonatal mouse calvariae. J Bone Miner Res 1991:6:3-8.

28. Ohsaki Y, Takahashi S, Scarcez T, et al. Evidence for an autocrine/paracrine role for interleukin- 6 in bone resorption by giant cell tumors of bone. Endocrinology $1992 ; 131: 2229-34$

29. Taga T, Hibi M. Hirata T, Yamasaki $K$, et al. Interleukin 6 triggers the association of its receptor with possible signal transducer, gp 130. Cell 1989:58:573-9.

30. Kishimoto T, Akira S, Taga T. Interleukin-6 and its receptor: a paradigme of cytokines. Science 1992;258:593-7.

31. Tamura T, Udagawa N, Takahashi N, et al. Soluble interleukin- 6 receptor triggers osteoclast formation by interleukin-6. Proc Natl Acad Sci USA 1993:90:11924-8.

32. Pfeilschifter J, Chenu C, Bird A, Mundy GR, Roodman GD. Interleukin-1 and tumor necrosis factor stimulate the formation of human osteoclast like cells in vitro. J Bone Miner Res 1989:4:113-8.

33. Uy HL, Dallas M, Calland JW, Boyce BF, Mundy GR, Roodman $G D$. Use of an in vivo model to determine the effects of interleukin- 1 on cells at different stages in osteoclast lineage. J Bone Min Res 1995:10:295-301.

34. Thomson BM, Saklatvala J, Chambers TJ. Osteoblasts mediate interleukin-1 stimulation of bone resorption by rat osteoclasts. J Exp Med 1986; 164: 104-12.

35. Felix $R$, Fleish $H$, Elford PR. Bone resorbing cytokines enhance release of macrophage colony stimulating activity by osteoblastic cell line MC3T3-El. Calcif Tissue Int 1989;44:356-60.

36. Jilka RL, Hangoc $G$, Girasole $G$, et al. Increased osteoclast development after estrogen loss: Mediation by IL6. Science 1992;257:88-91

37. Sarma U, Edwards M, Motoyoshi K, Flanagan AM. Inhibition of bone resorption by $17 \mathrm{~b}$-estradiol in human bone marrow cultures. J Cel Physiol 1998:175:99-108.

38. Zhang RW, Supowit SC, Xu X, et al. Expression of selected osteogenic markers in the fibroblast-like cells of rat marrow stroma. Calcif Tissue Int 1995;56:283-91.

39. Bellido T, Girassole $G$. Passeri $G$, et al. Demonstration of estrogen and vitamin $D$ receptors in bone marrow-derived stromal cells: up-regulation of estrogen receptors by 1,25dihydroxivitamin-D3. Endocrinology 1993;133:553-62.

40. Kuiper GGJM, Enmark E, Pelto-huikko M, Nilson S, Gustafsson JA. Cloning a novel estrogen receptor expressed in rat prostate and ovary. Proc Natl Acad Sci USA 1996:93:5925-30.

41. Gruber R, Czerwenka K, Wolf F, Ho GM, Willheim M. Peterlik $M$. Expression of the vitamin $D$ receptor, of estrogen and thyroid hormone receptor alpha and beta-isoforms, and of the androgen receptor in cultures of native mouse bone marrow and of stromal/osteoblastic cells. Bone 1999:24(5):465-73.

42. Eriksen EF, Colvard DS, Berg NJ, et al. Evidence of estrogen receptors in normal human osteoblast-like cells. Science 1988:41:84-6. 
43. Komm BS, Trepening CM. Benz DJ, et al. Estrogen binding receptor mRNA, and biologic response in osteoblastlike osteosarcoma cells. Science 1988;241:81-4.

44. Arts J, Kuiper GG, Janssen JM, et al. Differential expression of estrogen receptors alpha and beta mRNA during differentiation of human osteoblast SV-HFO cells. Endocrinology 1997; 138(11):5067-70.

45. Collier FM, Huang WH, Holloway WR, et al. Osteoclasts from human giant cell tumors of bone lack estrogen receptors. Endocrinology 1998: 139: 1258-67.

46. Pacifici R. Estrogen, cytokines and pathogenesis of postmenopausal osteoporosis. J Bone Miner Res 1996; 11:1043-51.

47. Manolagas SC, Jilka RL. Bone marrow, cytokines and bone remodeling. N Engl J Med 1995;332:305-11.

48. Girassole $G$, Jilka RL, Passeri $G$, et al. 17b-estradiol inhibits interleukin- 6 production by bone marrow stromal cells and osteoblasts in vitro: a potential mechanism for antiosteoporotic effect of estrogens. J Clin Invest 1992:89:883-91.

49. Poli V, Balena R, Fattori $E$, et al. Interleukin- 6 deficient mice are protectedfrom bone losscaused by estrogen depletion. EMBO J 1994; 13:1189-96.

50. Chaudhary LR, Spelsberg TC, Riggs BL. Production of various cytokines by normal human osteoblast-like cells in reponse to interleukin- $]$ and tumor necrosis factor-a: lack of regulation by $17 \mathrm{~b}$ - estradiol. Endocrinology 1992; 130:2528-34.

51. Kassem M, Khosla S, Spelsberg TC, Riggs L. Cytokine Production in the bone marrow microenviroment: Failure to demonstrate Estrogen Regulation in early postmenopausal women. J Clin Endocrinol Metab 1996;81:513-8.

52. Vargas SJ, Naprta A, Lee SK, et al, Lack of evidence for na increase in interleukin-6 Expression in adult murine bone, bone marrow, and marrow stromal cell cultures after ovarectomy. J Bone Miner Res 1996: 11:1926-34.

53. Cohen-Solal M, Graulet AM, Denne MA, Gueris J, Baylink D. De Vernejoul MC. Peripheral monocyte culture supernatants of menopausal women can induce bone resorption: involvement of cytokines. J Clin Endocrinol Metab 1993:77: 1648-53.

54. Manolagas SC. Role of cytokines in bone resorption. Bone 1995; 17:635-75.

55. Beresford JN, Joyner CJ, Devlin C, Triffit JT. The effects of dexamethasone and 1,25 hydroxyvitamin D3 on osteogenic differentiation of human marrow stromal cells in vitro. Arch Oral Biol 1994:39:941-7.

56. Keeting PE, Rifas L, Harris AS, Colvard DS, Spelberg TC, Peck WA, et al. Evidence for interleukin-1b production by cultured normal human osteoblast-like cells. J Bone Miner Res 1991;6:827-33

57. Kameda T, Mano H, Yuasa T, et al. Estrogen inhibits bone resorption resorption by directly inducing apoptosis of bone resorbing osteoclast. J Exp Med 1997; 186:489-95.
58. Hughes DE, Dai A, Tiffee JC, Li HH, Mundy GR, Boyce BF. Estrogen promotes apoptosis of murine osteoclasts mediated by TGF-B. Nature 1996;2: 1132-6.

59. Abu-amer Y, Tondravi MM. NF-Kb and Bone: The breaking point. Nature Med 1997;3:1 189-90.

60. Sun WH, Keller ET, Stebler BS, Ershler WB. Estrogen inhibits phorbol ester-induced $\mathrm{lkBa}$ transcription and protein degradation. Bioch Biophys Res Com 1998:244:691-5.

61. Kim GS, Kim CH, Choi CS, Park JY, Lee KU. Involvement of different second messengers in parathyroid hormoneand interleukin-1-induced interleukine- 6 and interleukin production in human bone marrow stromal cells. J Bone Miner Res 1997; 12:896-902.

62. Rougier F, Cornuu E, Praloran V, Denizot Y, IL-6 and IL-8 Production by human bone marrow stromal cells Cytokine 1998:10:93-7.

63. Love RR, Mazess RB, Barden HS, et al. Effects of tamoxifen on bone mineral density in postmenopausal women with breast cancer. N Engl J Med 1992;326:852-6.

64. Powles TJ, Davey JB, Mckinna A. A feasibility trial of tamoxifen chemoprevention of breast cancer in Great Britain, Cancer Invest 1988:6:621-4.

65. Delmas PD. Bjarnason NH, Mitlak BH. Effects of raloxifene on bone mineral density, serum cholesterol concentrations, and uterine endometrium in postmenopausal women. N Engl J Med 1997:337(23): 1641-7.

66. Ettinger B, Black DM, Mitlak BH. Reduction of vertebral fracture risk in postmenopausal women with osteoporosis treated with raloxifene. JAMA 1999;282:637-45.

67. Yang NN, Venogopalan M, Hardikar S, Glasebrook A. Identification of an estrogen response element activated by metabolites of $17 \mathrm{~b}$-estradiol and raloxifene. Science 1996:273:1222-6.

68. Evans G, Bryant HU, Magee D, Sato M, Turner RT. The effects of raloxifene on tibia histomorphometry in ovarectomized rats. Endocrinology 1994: 134:2283-8.

69. Heymann D, Guicheux J, Gouin F, Passuti N, Daculsi G. Cytokines, growth factors and osteoclasts. Cytokine 1998; $10: 155-8$.

70. Collin-Osdoby P, Oursler MJ, Webber D, Osdoby $P$. Osteoclast-specific monoclonal antibodies coupled to magnetic beads provide a rapid and efficient method of purifying avian osteoclasts, J Bone Min Res $1991: 6: 1353-65$

71. Oursler MJ, Osdoby P, Pyfferoen J, Riggs BL, Spelsberg IC. Avian osteoclasts as estrogen target cells. Proc Natl Acad Sci USA 1991:88:6613-7.

\section{Endereço para correspondência:}

Ana Claudia R. Ramalho

R. Território do Guaporé 363, apto 901 - Pituba

41.830-520 Salvador, Bahia 